\title{
CANADIAN JOURNAL OF
}

\section{Disability Studies}

Canadian Journal of Disability Studies

Published by the Canadian Disability Studies Association Association Canadienne des Études sur l'Incapacité

Hosted by The University of Waterloo

$\underline{\text { www.cjds.uwaterloo.ca }}$

cjdseditor@uwaterloo.ca

This document has been made accessible and PDF/UA compliant by Accessibil-IT Inc.

For more information go to

http://www.accessibilit.com 


\title{
Tremain, S. (Ed.) (2015). Foucault and the Government of Disability. Ann Arbor: University of Michigan Press. ISBN 978-0-472-03638-7.
}

\author{
Reviewed by Clint Jones
}

A decade ago, when it was originally published, this collection of essays was integral in raising awareness of, and shaping discussions about, disability related-issues in multiple fields of study. The collection is organized around a Foucauldian approach to bio-politics, genealogy, ethics, and, obviously, governance. This reissue of Shelley Tremain's vital collection of essays continues to focus on the importance of disability studies and while it has all the weight and significance of the original publication it also extends and builds upon those original essays. Tremain, rightly and accurately, characterizes the anniversary volume, like the original, as "a classic text in...critical disability theory and research" (9). It is, quite simply, a must read.

Foucault's significance to struggles in identity politics is well known and widely appreciated, but Tremain's collection of essays provides a robust and intensive use of Foucault's theories to develop critiques of both the medicalization of disabled bodies as well as the politicization of otherly abled persons. This is especially important given that disability has been, and continues to be, marginalized, even in those social movements most active in agitating for social equality and acceptance — feminist and queer studies and activism, for instance. The questions raised by and conclusions drawn from the arguments presented throughout the text open important venues in philosophical discourse about ontology and ethics. Using Foucault as the leaping off point for these discussions allows the contributors to advance Foucauldian theories about the institutional, structural, discursive, and material aspects of disability and lived experience while also challenging established philosophical projects concerned with the intersectionality of race, class, gender, and patriarchal norms. 
The organization of the book offers enough breadth to convey the wider significance of disability studies to other academic disciplines while also delving deeply enough into the issues presented that the urgency for a wider recognition of disability studies is made unmistakably clear. The foregoing, however, does not sacrifice accessibility to either Foucault or the discipline of disability studies. Everyone, from the curious layperson to the veteran academician, could pick up this book and be engaged by, challenged with, and exposed to new ideas without being overwhelmed by the content.

Foucault's philosophical projects were designed to interrogate communal structure, disposition, history, narrative, and purpose with an eye toward liberation. As such, no volume could rightly draw upon Foucault's thought without making those goals, at least in large part, its own as well. Tremain achieves this in her organization of the text into tightly knit units that offer concise and illuminating arguments in favour of a broader recognition of disability. The four original sections are kept intact in the anniversary edition and address epistemologies and ontologies, histories, governmentalities, and ethics and politics —all of which are still as timely for current public discourse as they were a decade ago. However, this celebratory re-issue includes a fifth section on disability and governmentality which brings new voices into the discussion and allows for the text to address new issues relevant to disability studies.

These five sections coalesce around important themes that require further fervent philosophical discussion, but are themselves an impressive vanguard opening up spaces for examination. Addressing, among other things, the crisis of the subject and negative ontologies section one utilizes Foucauldian philosophy to expose the fissures and cracks in modern identities along the fault lines of subjugation, control, and integrity, where subjectivity and transgression are the tools used to shaped legal identities. Section two presents genealogical 
investigations of important elements of disability worthy of Foucault himself. Using historical approaches to what were once called mental retardation, sensory deficiencies, and physical anomalies that entrenched ideas about deformity, its social categorization, and attempts to make it invisible, are brought to light. Section three tackles the difficult issues of mobility, space, and productivity questioning, in classic Foucauldian ways, conformity, deviation, and penalties as these are directed by governments - authoritative bodies of power that define normalcy. Here we confront head on the many and numerous difficulties faced by disabled members of society struggling to redefine their existence both individually and in relation to society writ large while simultaneously striving to overcome a differentiation that is, all too often, marked out on the surface of their being. The final section of original content navigates the murky waters of moral problems created when inclusion is accomplished vis-à-vis accommodation and ethical discourse is about how to politely distance ourselves from these problems while remaining empathetic.

The re-issue also contains a new section of material that deals with problems that have either developed a robustness they once lacked or that have been created by a malign public discourse rooted in ignorance but nonetheless finding a sympathetic audience. Most importantly this section addresses anti-vaxxers and autism. However, while this extends the analysis of section two, it is important to keep in mind how conversations of this type apply to the heady dialogue surrounding psychiatric disability in general especially where gun control lurks in the shadows. Additionally, the problems of empire and citizenship, the scope of which can be as narrow as the right to die and as broad as to whom medical access should be given. Section five, along with the other new material included in the re-issue, are all welcome and timely additions.

The re-issuing of this text is meant to be a celebration of the decade long impact Tremain's collection of essays has had on the discussion about disability across academia. It 
rightly deserves to be celebrated for that reason alone. However, this newly updated version deserves to be celebrated in its own right as it will most certainly continue, over the next decade, to inform the discussions, highlight the controversies, and champion the rights and recognitions owed to the many people, past and present, whose existence is the subject matter of this book. 